J. Dairy Sci. 94:5247-5247

doi:10.3168/jds.2011-94-10-5247

(C) American Dairy Science Association ${ }^{\circledR}, 2011$.

\title{
Erratum to "Comparison of bulk-tank standard plate count and somatic cell count for Wisconsin dairy farms in three size categories" (J. Dairy Sci. 94:4237-4241)
}

\section{S. C. Ingham, Y. Hu, and C. Ané}

An error was noted in the units for SPC and SCC in Table 1; the corrected table is shown below. The authors regret the error.

\section{REFERENCES}

Ingham, S. C., Y. Hu, and C. Ané. 2011. Comparison of bulk-tank standard plate count and somatic cell count for Wisconsin dairy farms in three size categories. J. Dairy Sci. 94(8):4237-4241.

Table 1. Group mean values for minimum, median, mean 90th percentile, and SPC and SCC for small $(\leq 118$ cows), large (119-713 cattle), and confined animal feeding operations (CAFO; $\geq 714$ cattle) farm size categories

\begin{tabular}{lccc}
\hline Item & $\begin{array}{c}\text { Small farms } \\
(\mathrm{n}=12,866)\end{array}$ & $\begin{array}{c}\text { Large farms } \\
(\mathrm{n}=1,565)\end{array}$ & $\begin{array}{c}\text { CAFO farms } \\
(\mathrm{n}=160)\end{array}$ \\
\hline SPC & & & \\
Minimum & $25,700^{\mathrm{a}}$ & $25,100^{\mathrm{b}}$ & $25,000^{\mathrm{ab}}$ \\
Median & $31,300^{\mathrm{a}}$ & $26,000^{\mathrm{b}}$ & $25,400^{\mathrm{b}}$ \\
Mean & $58,700^{\mathrm{a}}$ & $36,300^{\mathrm{b}}$ & $35,000^{\mathrm{ab}}$ \\
90th percentile & $100,100^{\mathrm{a}}$ & $46,800^{\mathrm{b}}$ & $40,500^{\mathrm{b}}$ \\
Maximum & $250,200^{\mathrm{a}}$ & $110,500^{\mathrm{b}}$ & $113,600^{\mathrm{ab}}$ \\
SCC & & & \\
Minimum & $209,000^{\mathrm{a}}$ & $183,000^{\mathrm{b}}$ & $179,000^{\mathrm{ab}}$ \\
Median & $348,000^{\mathrm{a}}$ & $266,000^{\mathrm{b}}$ & $239,000^{\mathrm{c}}$ \\
Mean & $369,000^{\mathrm{a}}$ & $273,000^{\mathrm{b}}$ & $240,000^{\mathrm{c}}$ \\
90th percentile & $51,000^{\mathrm{a}}$ & $344,000^{\mathrm{b}}$ & $288,000^{\mathrm{c}}$ \\
Maximum & $625,000^{\mathrm{a}}$ & $394,000^{\mathrm{b}}$ & $313,000^{\mathrm{c}}$ \\
\hline
\end{tabular}

$\overline{{ }^{a-c} \text { Different superscript letters within a row indicate that } P<0.017 \text { for pairwise comparison of group means }}$ using the Wilcoxon rank sum test. 